\title{
Salmon-Colored and White Areas on Dermoscopy as Supportive Findings in the Diagnosis of Primary Cutaneous Marginal Zone Lymphoma
}

\author{
Giovanni Biondo ${ }^{1,2}$, Simona Sola ${ }^{3}$, Carlotta Pastorino ${ }^{2}$, Cesare Massone ${ }^{2}$
}

1 Dermatology and Sexually Transmitted Disease Unit, P. Giaccone Hospital, University of Palermo, Palermo, Italy
2 Dermatology Unit, Galliera Hospital, Genoa, Italy
3 Surgical Pathology, Galliera Hospital, Genoa, Italy

Key words: dermoscopy, lymphoma, cancer

Citation: Biondo G, Sola S, Pastorino C, Massone C. Salmon-colored and white areas on dermoscopy as supportive findings in the diagnosis of primary cutaneous marginal zone lymphoma. Dermatol Pract Concept. 2019;9(1):63-66. DOI: https:/doi.org/10.5826/ dpc.0901a14

Published: January 31, 2019

Copyright: $@ 2019$ Biondo et al. This is an open-access article distributed under the terms of the Creative Commons Attribution License, which permits unrestricted use, distribution, and reproduction in any medium, provided the original author and source are credited.

Funding: None.

Competing interests: The authors have no conflicts of interest to disclose.

Authorship: All authors have contributed significantly to this publication.

Corresponding author: Cesare Massone, MD, Dermatology Unit, Ospedali Galliera, Via Volta 6, 16128, Genova, Italy. Email: cesare. massone@galliera.it

\section{Introduction}

Dermoscopy can be a useful tool to help clinicians in the diagnosis of cutaneous B-cell lymphomas.

\section{Case Presentation}

A 61-year-old man presented with an irregularly growing erythematous plaque measuring $28 \times 35 \mathrm{~mm}$, which had appeared on the left thigh a few months before (Figure 1A). He was otherwise healthy and could not recall an arthropod bite or a trauma in the same area. He was not taking any drugs and did not report weight loss, fever, or night sweating. The physical examination was normal. Upon polarized noncontact dermoscopy, we observed a diffuse salmon-colored area with focally white areas (Figure 1B).

The lesion was totally excised with differential diagnosis of granulomatous dermatosis, amelanotic melanoma, cutaneous lymphoma, sarcoma, or metastasis. Histopathology showed a dense nodular dermal lymphocytic infiltrate extend-

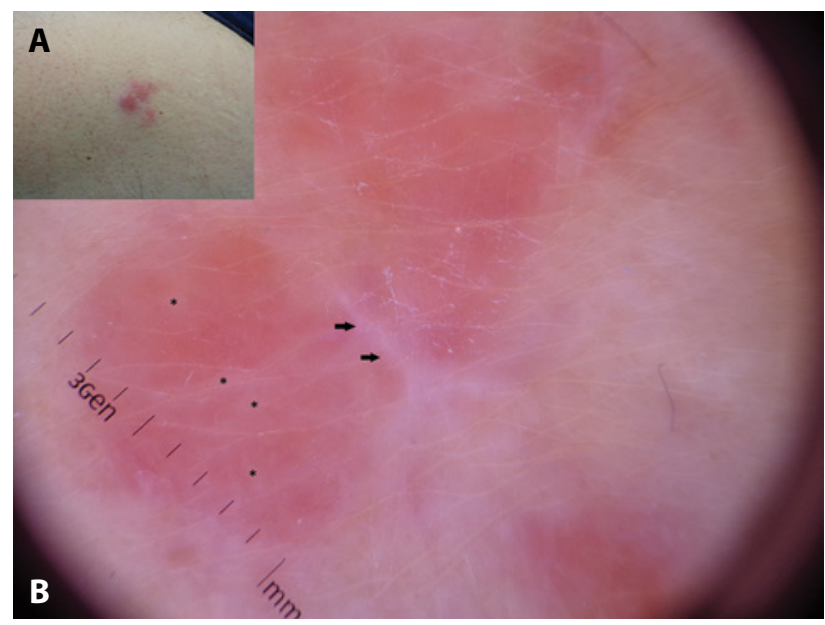

Figure 1. (A) Irregular erythematous plaque on the left thigh. (B) Polarized noncontact dermoscopy: A diffuse salmon-colored area on the background, together with focally white areas (marked with black arrows) and white circles (marked with asterisks). [Copyright: (c)2019 Biondo et al.] 


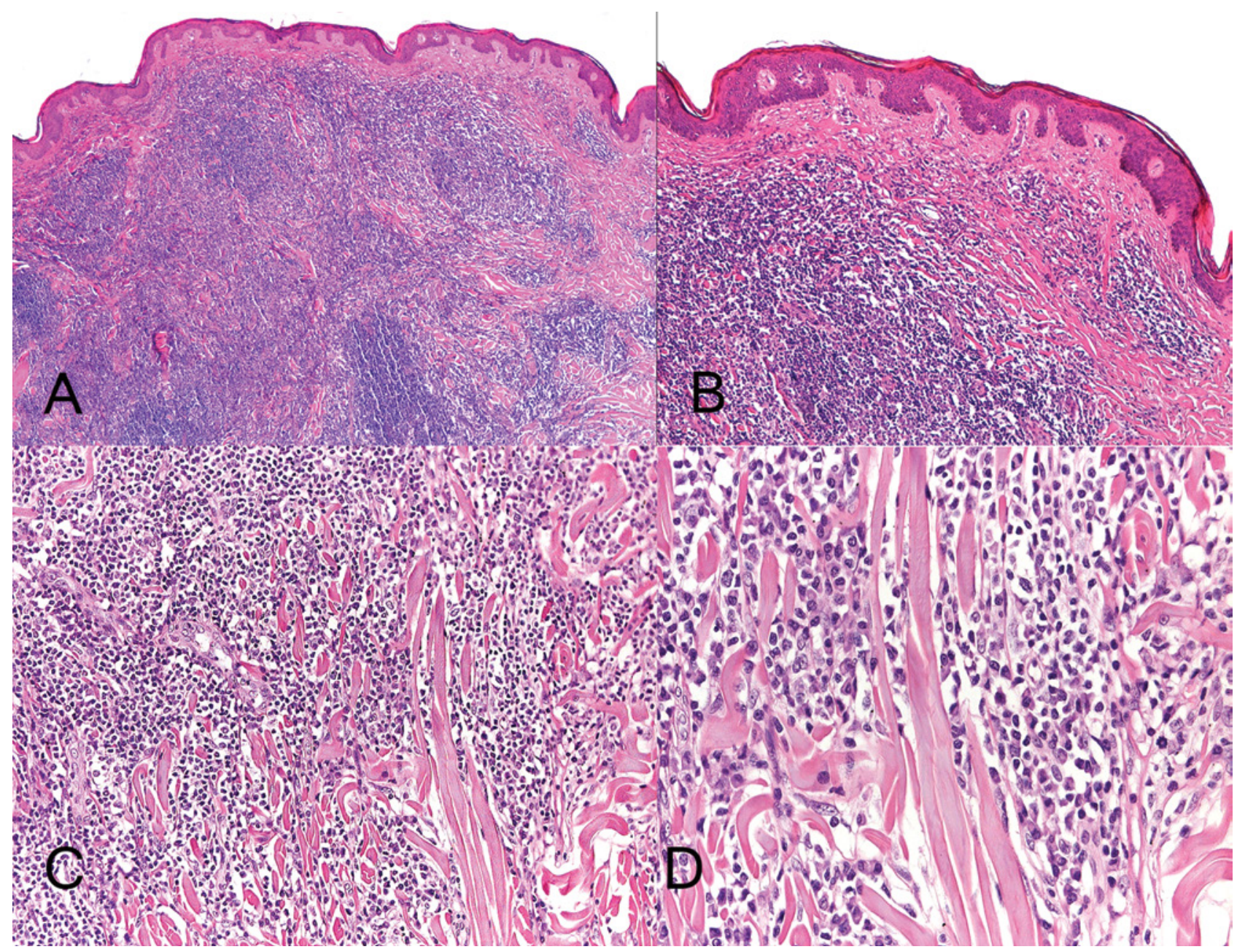

Figure 2. (A) Below a clear-cut grenz zone in the papillary dermis, there is a dense nodular dermal lymphocytic infiltrate composed of reactive lymphoid follicles surrounded by small to medium-sized cells (marginal zone cells). No dilated vessels in the papillary dermis are seen; areas of reactive fibrosis in the dermis are present (hematoxylin and eosin $[\mathrm{H} \& \mathrm{E}], \times 20$ ). (B) Focally, the grenz zone is reduced due to patchy, nodular, more superficial infiltrate in the papillary dermis $(\mathrm{H} \& \mathrm{E}, \times 100)$. (C) Marginal zone cells, plasma cells, lymphoplasmacytoid cells, and slight increase of vessels within the infiltrate (H\&E, $\times 200)$. (D) Plasma cells and lymphoplasmacytoid cells (H\&E, ×400). [Copyright: (C2019 Biondo et al.]

ing to the subcutaneous fat composed of reactive lymphoid follicles surrounded by a diffuse infiltrate composed by small to medium sized cells (marginal zone cells). In addition, plasma cells (at the margins of the infiltrate), lymphoplasmacytoid cells, small reactive lymphocytes, and occasional eosinophils were observed.

A clear-cut grenz zone between the infiltrate and the epidermis was present (Figure 2). Neoplastic cells stained positive for $\mathrm{CD} 20$ and $\mathrm{CD} 79 \mathrm{a}$; cells stained negative for Bcl-6, Bcl-2, CD5, and CD10; reactive T lymphocytes were $\mathrm{CD} 3+$. A monoclonal expression of kappa chain was found. Further complete staging investigations were negative for nodal or systemic involvement. Following WHO criteria [1], primary cutaneous marginal zone lymphoma (PCMZL) was diagnosed.

\section{Discussion}

PCMZL is a low-grade malignant primary cutaneous B-cell lymphoma (PCBCL). Clinically, patients present with solitary or multiple, asymptomatic, rarely ulcerative pink-violet to red-brown papules, plaques, and nodules localized preferentially on the extremities or trunk. Mascolo et al. described the dermoscopic features of 10 PCBCL cases, observing white circles with a salmon-colored area in 9/10 cases, scales in 7/10 cases, and arborizing vessels or a polymorphous vascular pattern in 5 and 2 cases, respectively [2]. Piccolo et al. also described the same features in 2 additional patients [3]. Geller et al. expanded the study, examining 58 dermoscopic images of PCBCLs, and reported a salmon-colored area $(79.3 \%)$ and prominent blood vessels $(77.6 \%)$, mostly of serpentine (linear-irregular) morphology (67.2\%) [4]. Ghahramani observed 


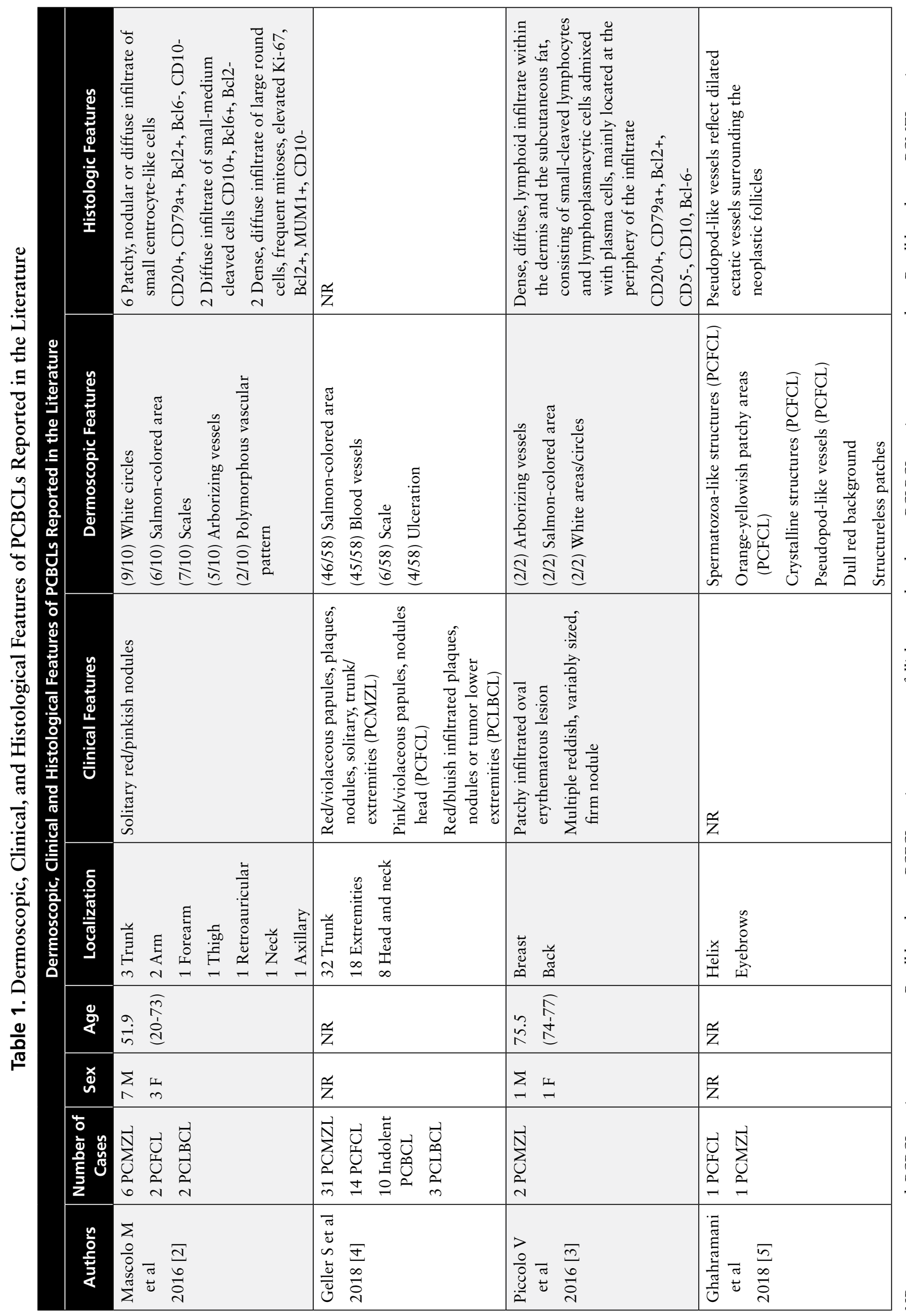

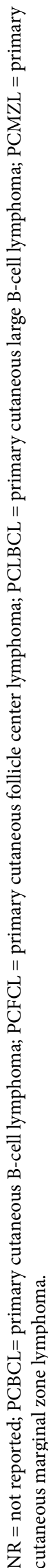


spermatozoa-like structures, orange-yellowish patchy areas, crystalline structures, and pseudopod-like vessels in primary cutaneous follicle center lymphoma, but not in PCMZL [5]. These findings are summarized in Table 1.

Our observation confirms that a salmon-colored area upon dermoscopy is typical even if not exclusive of PCBCL. In fact, it brings to mind the orangish-yellowish areas observed in granulomatous dermatoses such as sarcoidosis, lupus vulgaris, and granulomatous rosacea, where also linear branching vessels are seen [6,7], while granuloma annulare shows peripheral structureless reddish-yellowish-orange areas with variable blurry vessels $[8,9]$. It is difficult to correlate the salmon color of PCBCL with pathology; an explanation could reside in the increased vascularization inside the dense nodular neoplastic lymphoid infiltrate in the mid and deep dermis (Figure 2C). White areas probably correlate with areas of reactive fibrosis in the dermis or might correlate with focally reduced grenz zone due to patchy, nodular, more superficial infiltrate in the papillary dermis (Figure 2B). Recently, pseudopod-like vessels have been correlated with dilated ectatic vessels surrounding the neoplastic follicles [5].

As further dermoscopic differential diagnosis, amelanotic melanoma shows dotted vessels,

linear-irregular vessels, hairpin-irregular vessels, serpentine vessels, or a combination of them (polymorphic vessels); also milky-red areas can be frequently visualized [10]. Contrary to previous experiences [2,3], in our patient prominent vessels with serpentine morphology were not observed. Also on dermoscopic-pathologic correlation, no dilated vessels were observed in the superficial dermis; prominent blood vessels have been correlated with neoangiogenesis, a phenomenon that in our case probably did not occur yet in the superficial dermis because it might be correlated with a different stage of the disease.

\section{Conclusions}

In conclusion, a salmon-colored area and white areas on dermoscopy might be suggestive, even if not unique, of PCBCL, supporting clinicians in recognizing primary lesions and recurrences [11], moreover identifying correct site of biopsy.

\section{References}

1. Cook JR, Isaacson PG, Chott A, et al. Extranodal marginal zone lymphoma of mucosa-associated lymphoid tissue (MALT lymphoma). In: Swerdlow SH, Campo E, Harris NL, et al, eds. WHO Classification of Tumours of Haematopoietic and Lymphoid Tissues. 4th ed. Lyon Cedex: IARC; 2017:259-262.

2. Mascolo M, Piccolo V, Argenziano G, et al. Dermoscopy pattern, histopathology and immunophenotype of primary cutaneous Bcell lymphoma presenting as a solitary skin nodule. Dermatology. 2016;232(2):203-207.

3. Piccolo V, Mascolo M, Russo T, Staibano S, Argenziano G. Dermoscopy of primary cutaneous B-cell lymphoma (PCBCL). J Am Acad Dermatol. 2016;75(4):e137-e139.

4. Geller S, Marghoob AA, Scope A, Braun RP, Myskowski PL. Dermoscopy and the diagnosis of primary cutaneous B-cell lymphoma. J Eur Acad Dermatol Venereol. 2018;32(1):53-56.

5. Ghahramani GK, Goetz KE, Liu V. Dermoscopic characterization of cutaneous lymphomas: a pilot survey. Int J Dermatol. 2018;57(3):339-343.

6. Bombonato C, Argenziano G, Lallas A, Moscarella E, Ragazzi M, Longo C. Orange color: a dermoscopic clue for the diagnosis of granulomatous skin diseases. J Am Acad Dermatol. 2015;72(1 Suppl):S60-S63.

7. Brasiello M, Zalaudek I, Ferrara G, et al. Lupus vulgaris: a new look at an old symptom-the lupoma observed with dermoscopy. Dermatology. 2009;218(2):172-174.

8. Errichetti E, Lallas A, Apalla Z, Di Stefani A, Stinco G. Dermoscopy of granuloma annulare: a clinical and histological correlation study. Dermatology. 2017;233(1):74-79.

9. Bañuls J, Arribas P, Berbegal L, DeLeón FJ, Francés L, Zaballos P. Yellow and orange in cutaneous lesions: clinical and dermoscopic data. J Eur Acad Dermatol Venereol. 2015;29(12):2317-2325.

10. Zalaudek I, Kreusch J, Giacomel J, Ferrara G, Catricalà C, Argenziano G. . How to diagnose nonpigmented skin tumors: a review of vascular structures seen with dermoscopy, part I: melanocytic skin tumors. J Am Acad Dermatol. 2010;63(3):361-374.

11. Piccolo V, Russo T, Agozzino M, et al. Dermoscopy of cutaneous lymphoproliferative disorders: where are we now? Dermatology. 2018;234(3-4):131-136. 